\title{
QUALITY OF LIFE AND ITS ASSOCIATION WITH CARDIOVASCULAR RISK FACTORS IN A COMMUNITY HEALTH CARE PROGRAM POPULATION
}

\author{
Luiz Mário Baptista Martinelli, Bruno Moreira Mizutani, Anibal Mutti, Maria \\ Paula Barbieri D`elia, Rodrigo Soler Coltro, Beatriz Bojikian Matsubara
}

doi: 10.1590/S1807-59322008000600013

\begin{abstract}
Martinelli LMB, Mizutani BM, Mutti A, D`elia MPB, Coltro RS, Matsubara BB. Quality of life and its association with cardiovascular risk factors in a Community Health Care Program population. Clinics. 2008;63:783-8.
\end{abstract}

OBJECTIVE: To evaluate quality of life in a population that attended a specific community event on health care education, and to investigate the association of their quality of life with the presence of cardiovascular risk factors

INTRODUCTION: Interest in health-related quality of life is growing worldwide as a consequence of increasing rates of chronic disease. However, little is known about the association between quality of life and cardiovascular risk factors.

METHODS: This study included 332 individuals. Demographics, blood pressure, body mass index, and casual glycemia were evaluated. The brief version of the World Health Organization Quality of Life questionnaire on quality of life was given to them. The medians of the scores obtained for the physical, psychological, emotional, and environmental domains were used as cutoffs to define "higher" and "lower" scores. A multinomial logistic regression model was used to define the parameters associated with lower scores.

RESULTS: Diabetes mellitus, dyslipidemia, and obesity were associated with lower scores in the physical domain. Dyslipidemia was also associeted with lower scores in the psychological domain. Male gender and regular physical activity had protective effects on quality of life. Aging was inversely associated with decreased quality of life in the environmental domain.

CONCLUSION: The presence of cardiovascular risk factors is related to a decreased quality of life. Conversely, male gender and regular physical activity had protective effects on quality of life. These findings suggest that exercising should be further promoted by health-related public programs, with a special focus on women.

KEYWORDS: Blood pressure; Old age; Diabetes mellitus; Obesity; Female gender.

\section{INTRODUCTION}

The increasing in expectation of life is associated with a higher prevalence of chronic disease, which may lead to physical limitations and reduce quality of life. Cardiovascular diseases (CVD) are a principal cause of deaths in Brazil. ${ }^{1}$ Furthermore, they represent the greatest expenditure in medical assistance by the central governmental health provider, Sistema Único de Saúde (SUS). ${ }^{2}$ Increasing prevalence of CVD is seen

Disciplina de Cardiologia, Departamento de Clínica Médica, Faculdade de Medicina de Botucatu, UNESP - São Paulo/SP, Brazil .

Email: beatrizm@fmb.unesp.br

Tel.: 55143882.2969

Received for publication on July 21, 2008

Accepted for publication on September 8, 2008 not only in Brazil, but also other countries, regardless of their level of socioeconomic development. ${ }^{3,4}$

In the majority of cases, CVD have well known etiologies and risk factors. ${ }^{5}$ The World Health Organization (WHO) classifies the risk factors into two groups, those related to the individual and those related to the environment. The individual risk factors are: general (age, sex, formal education level, heredity), associated with lifestyle (tobacco use, diet, sedentary lifestyle), and intermediate or biological [systemic arterial hypertension (AH), obesity, dyslipidemia, diabetes mellitus (DM)]. Environmental risk factors consist of urbanization and socioeconomic, cultural, and environmental conditions. ${ }^{6-8}$ Nationwide studies have shown that these factors may contribute to the risk of acute myocardial infarction. ${ }^{9,10}$ 
Beginning in the 1990s, general cardiovascular risk was assessed in the individuals and populations, driving preventive measures and approaches to treat and control cardiovascular diseases. The general cardiovascular risk assesses to what extent a specific combination of cardiovascular risk factors are present simultaneously in the same person. ${ }^{11}$

This approach has led quality of life to be included as a relevant aspect in the evaluation of individuals' health. The identification of clinical variables that reduce quality of life should help to ensure the adoption of health measures with the greatest possible impact on their target populations. ${ }^{12}$ There are two main conceptualizations of quality of life, one that is more generic and another that relates specifically to health. ${ }^{13-15}$

Despite the relevance this issue, little is known about quality of life in the population. In addition, no studies have investigated the possibility that the presence of individual risk factors for CVD is associated with decreased quality of life. Therefore the present study aimed to evaluate quality of life in a population that voluntarily visited a specific community health education event, and to analyze whether their quality of life was associated with the presence of cardiovascular risk factors.

\section{METHODS}

The study retrospectively evaluated 332 completed WHOQOL questionnaires (brief version), ${ }^{16}$ as well as demographic and physical data of volunteers participating in a community event on health education held in May of 2006 in Botucatu, localized in the central region of the state of Sao Paulo. This event was an annual event promoted by a student association of the School of Medicine, student groups participated and professors acted as advisors. This event occurred in a public park on a weekend following extensive publicity in the local media. All of the volunteers signed consent forms, thereby agreeing to participate in the research. The project was submitted to and approved by the Research Ethics Committee of the Botucatu Medical SchoolUnesp (Of.053/08-CEP).

The individuals were interviewed by trained medical students to obtain information on personal and familial antecedents, life conditions, and habits. Individuals were also questioned about their access to information on cardiovascular risk factors.

After the interview, each subject's weight and height were measured using a conventional electronic balance. Arterial pressure was taken with an aneroid sphygmomanometer after the individual had rested for five minutes in a seated position. Glycemia was measured using Roche portable glycemia monitors (Accu-Chek Active model) and Roche Accu-Chek reagent strips. For this test, a drop of blood was obtained by finger puncture using standard disposable material.

The following values were considered normal: systolic arterial pressure $\leq 140 \mathrm{mmHg}$; diastolic arterial pressure $\leq 90 \mathrm{mmHg}$; casual glycemia $\leq 200 \mathrm{mg} / \mathrm{dl}$. Individuals were considered hypertensive or diabetic if they self-reported the disease or if they were under specific treatment.

The body mass index (BMI, $\left.\mathrm{kg} / \mathrm{m}^{2}\right)$ was calculated from values of weight $(\mathrm{P}, \mathrm{kg})$ and height $(\mathrm{A}, \mathrm{m})$ as follows: $\mathrm{BMI}=\mathrm{P} / \mathrm{A}^{2}$. Values greater than or equal to $25 \mathrm{~kg} / \mathrm{m}^{2}$ were considered indicative of being overweight or obese.

Quality of life scores were calculated from the responses to the WHOQOL questionnaire (brief version), which includes 26 questions that evaluate the following domains and the facets within these domains ${ }^{17}$ :

- Physical: pain and discomfort, energy and fatigue, sleep and rest, mobility, daily life activities, undergoing medication or other treatment, work capacity.

- Psychological: positive sentiments; thinking, learning, memory and concentration; self-esteem; body image and appearance; negative sentiments; spirituality/religion/ personal beliefs.

- Social relations: personal relations, social support, sexual activity.

- Environment: physical safety and protection, environment in the home, financial resources, availability and quality of social and health care, opportunities for acquiring new information and abilities, participation in recreation/leisure opportunities, physical environment, such as level of pollution, noise, traphic, climate and transport.

Guidelines in the literature were followed for calculating the scores ${ }^{18}$ using the statistical package SigmaStat for Windows (version 2.03, SPSS, Inc.). The median values of scores in the WHOQOL four domains were taken as the threshold for defining higher and lower scores.

Single-variable comparisons were performed using Student's t-test or the Mann-Whitney or Chi-square test. A multinomial logistic regression model was used to identify variables associated with a lower score for quality of life. Variables introduced in the model were gender, age, DM, $\mathrm{AH}$, self reported dyslipidemia, regular practice of physical exercises (at least three times a week), tobacco use, and access to information on cardiovascular risk. In all analyses, the level of significance was defined at $\mathrm{p}<0.05$.

\section{RESULTS}

Means and standard deviations of the clinical variables measured in the study population (146 men and 186 women) are shown in Table 1 . There were no differences between 
Table 1 - Comparison of clinical variables between women and men in the study

\begin{tabular}{lcccc}
\hline Variable & $\begin{array}{c}\text { Total } \\
(\mathrm{n}=332)\end{array}$ & $\begin{array}{c}\text { Women } \\
(\mathrm{n}=186)\end{array}$ & $\begin{array}{c}\text { Men } \\
(\mathrm{n}=146)\end{array}$ & p value \\
\hline Age $($ years $)$ & $57 \pm 14$ & $56 \pm 15$ & $58 \pm 13$ & 0.185 \\
BMI $\left(\mathrm{kg} / \mathrm{m}^{2}\right)$ & $28 \pm 5.1$ & $28.4 \pm 5.8$ & $27.6 \pm 4.1$ & 0.173 \\
SAP $(\mathrm{mmHg})$ & $130 \pm 18.0$ & $130 \pm 18$ & $132 \pm 18$ & 0.135 \\
DAP $(\mathrm{mmHg})$ & $82 \pm 11.8$ & $81 \pm 12$ & $84 \pm 12$ & 0.037 \\
$\begin{array}{l}\text { Casual glycemia } \\
(\mathrm{mg} / \mathrm{dL})\end{array}$ & $112 \pm 45$ & $113 \pm 45$ & $113 \pm 47$ & 0.896 \\
\hline
\end{tabular}

$\mathrm{BMI}=$ body mass index; SAP and DAP = systolic and diastolic arterial pressure

men and women, except for higher diastolic arterial pressure observed among the men $(84 \pm 12 \mathrm{mmHg}$ vs. $81 \pm 12 \mathrm{mmHg}$; $\mathrm{p}=0.037)$. In the study population, 155 individuals were aged $\geq 60$ years (46\%); of these, $87(56 \%)$ were women.

Considering the entire study population, 219 (66\%) had a BMI $\geq 25 \mathrm{~kg} / \mathrm{m}^{2}, 162(48.8 \%)$ were classified as hypertensive, and 67 (20.2\%) had DM. Nearly one-third (26.8\%) reported being dyslipidemic and $10.5 \%$ reported that they were using tobacco at the time of the study, while $31 \%$ reported prior but not present tobacco use. Among all of the study participants, $47.6 \%$ denied regular practice of physical exercises, and 107 (32\%) reported having access to information on cardiovascular risk factors.

The distribution of quality of life scores in the study population is shown in Figure 1. The medians and their respective interquartile ranges were: 71.4 (60.7-82.1) in the physical domain, 70.8 (62.5-79.2) in the psychic domain, 75.0 (58.3-83.3) in the social domain, and 62.5 (56.3-75.0) in the environmental domain. The comparison between men

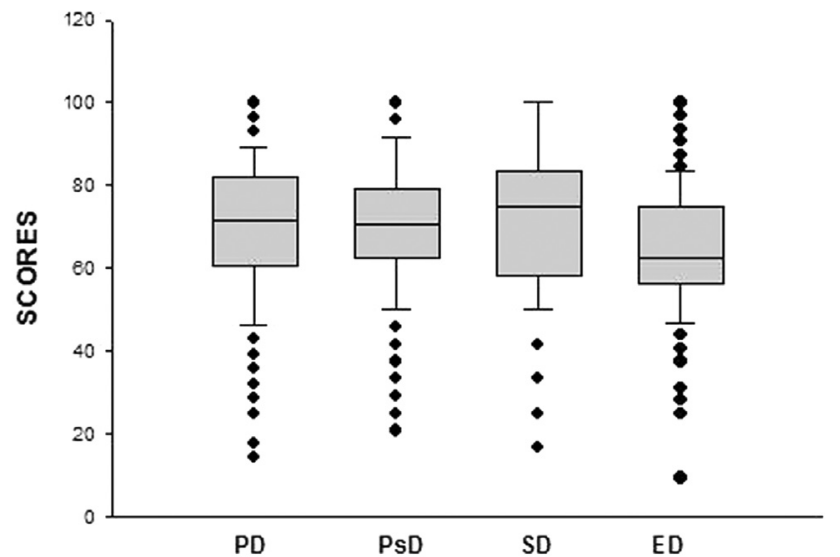

Figure 1 - Box plot showing the distribution of scores of quality of life in physical (PD), psychological (PsD), social (SD), and environment domains (ED). The central line represents the median, and the lower and upper limits represent the $25^{\text {th }}$ and $75^{\text {th }}$ percentiles, respectively. The vertical lines represent the $10^{\text {th }}$ and $90^{\text {th }}$ percentiles, while the symbols indicate the extrapolated values that define these limits. and women revealed significant differences in the social domain $(\mathrm{p}=0.03)$ and the psychological domain $(\mathrm{p}<0.001)$, with lower scores observed for the female gender.

Tables 2-4 show statistically significant results obtained with the multinomial logistic regression model. In the physical domain, lower scores for quality of life were associated with DM, dyslipidemia, and BMI $\geq 25 \mathrm{~kg} / \mathrm{m}^{2}$. The male gender showed a protective effect; that is, being a man reduced the chance of a lower score in the physical domain by $45 \%$. In the psychological domain, maleness and regular practice of physical exercise were inversely associated with lower scores (Table 3). In the case of the environmental domain, being at least 60 years old and regularly practicing physical exercise were inversely associated with lower scores (Table 4). No variables were found to be independently associated with quality of life scores in the social domain.

Table 2 - Logistic regression model to explain the lower scores in the physical domain

\begin{tabular}{lccc}
\hline Factor & $\mathrm{p}$ value & $\hat{\mathrm{OR}}$ & $95 \% \mathrm{CI}$ \\
\hline Intercept & 0.029 & 0.525 & \\
Male Gender & 0.016 & 0.556 & $(0.345-0.895)$ \\
BMI $\left(\mathrm{kg} / \mathrm{m}^{2}\right)$ & 0.022 & 1.878 & $(1.094-3.223)$ \\
Dyslipidemia & 0.004 & 1.516 & $(1.146-2.006)$ \\
DM & 0.003 & 2.62 & $(1.382-4.968)$ \\
\hline
\end{tabular}

$\mathrm{X}^{2}=32.2 ; \mathrm{gl}=4 ; \mathrm{p}<0.001$

Table 3 - Logistic regression model to explain lower scores in the psycological domain

\begin{tabular}{lccc}
\hline Factor & $\mathrm{p}$ value & $\hat{\mathrm{OR}}$ & $95 \% \mathrm{CI}$ \\
\hline Intercept & 0.509 & 0.85 & \\
Male Gender & $<0.001$ & 0.40 & $(0.240-0.666)$ \\
Dyslipidemia & $<0.001$ & 1.845 & $(1.372-2.481)$ \\
Regular Physical & $<0.001$ & 0.403 & $(0.245-0.661)$ \\
Exercise & & & \\
\hline
\end{tabular}

$\mathrm{X}^{2}=45.07 ; \mathrm{gl}=3 ; \mathrm{p}<0.001$

Table 4 - Logistic regression model to explain lower scores in the environmental domain

\begin{tabular}{lccc}
\hline Factor & $\mathrm{p}$ value & $\hat{\mathrm{OR}}$ & $95 \% \mathrm{CI}$ \\
\hline Intercept & 0.042 & 2.892 & \\
Age (years) & 0.024 & 0.981 & $(0.964-0.997)$ \\
Dyslipidemia & 0.011 & 1.423 & $(1.083-1.870)$ \\
$\begin{array}{l}\text { Regular Physical } \\
\text { Exercise }\end{array}$ & 0.039 & 0.613 & $(0.386-0.975)$ \\
\hline
\end{tabular}

$\mathrm{X}^{2}=16.94 ; \mathrm{gl}=3 ; \mathrm{p}=0.001$ 
Unadjusted analyses show that lack of access to information about cardiovascular risk factors prevented a higher score in the environmental domain (OR: 0.57; IC95\%, 0.36-0.91; $\mathrm{p}=0.018$ ), although this association was not significant based on the multinomial logistic regression model.

\section{DISCUSSION}

The present study aimed to evaluate quality of life in a specific population, which was composed mainly of individuals aged more than 50 years who showed a high prevalence of cardiovascular risk factors. In addition, the study sought to examine whether the presence of these risk factors reduced their quality of life.

The high frequencies of $\mathrm{AH}$, hypercholesterolemia, tobacco use, DM, sedentary lifestyle, and elevated BMI in the study sample reflects the fact that participants were recruited from among individuals who voluntarily sought free health-related education and monitoring for CVD.

For instance, although the mean arterial pressure values for the participant sample were within normal limits, nearly half of the participants qualified as being hypertensive. This frequency is higher than that described in previous population studies ${ }^{19-21}$. Nunes Filho et $\mathrm{al}^{22}$ found the following risk factor frequencies in their study: $\mathrm{AH}, 14.7 \%$; DM, 2.3\%; tobacco use, $15.6 \%$; dyslipidemia, $18.75 \%$; and obesity, $15.6 \%$.

In a recent study, Rozanski et al. ${ }^{24}$ divided the psychological and social alterations into two general categories in the context of quality of life: (1) emotional factors, which include affective disorders such as clinical depression and anxiety disorders, as well as hostile behavior and rage; (2) chronic stressors, which include factors such as low social support and socioeconomic level, workplace stress, stress in marriage, and the stress of providing assistance to sick family members. The authors showed that patients with myocardial infarction and depressive symptoms presented significantly higher mortality within five years than patients without symptoms of depression. In the same study, depressive mood was associated with a $49 \%$ increase in the risk of coronary atherosclerotic disease.

Few studies in Brazil have attempted to evaluate the association between cardiovascular risk factors and quality of life. A recent study by Cavalcante et al..$^{23}$, which included hypertensive patients, reported average scores between 60 and 70 (on a scale of 0-100) in different domains, as evaluated by another quality of life questionnaire. These values are very close to those found in our study, even though those authors used a different instrument to evaluate quality of life.
The present study found that the presence of chronic diseases that confer a higher risk of CVD was inversely associated with quality of life scores. These results are in agreement with others who evaluated the impact of chronic diseases and higher cardiovascular risk on quality of life. . $2,20,23-26^{2}$

It is interesting to note that the present study found women to score lower on quality of life domains, consistent with the findings of other studies. Previous studies have reported lower scores for quality of life for females due to deteriorating mental health. ${ }^{25}$ In their analysis of quality of life scores in a population aged 60 years or older, in a city in the central region of the state of Minas Gerais, Pereira et al. ${ }^{26}$ observed that men showed higher scores than women in the physical, psychological, and environmental domains. Our present study shows similar results, indicating that maleness reduces the chances of scoring lower in the physical and psychological domains by $45 \%$ and $60 \%$, respectively. The most important causes for women's quality of life are not well understood. They have been attributed to factors that contribute to low self-esteem, overwork, and perhaps workplace difficulties..$^{27}$ It has also been argued that women verbalize more than men during interviews concerning quality of life, which may partly explain the difference in their scores. ${ }^{28}$

Jiang and Hesser ${ }^{20}$ have described lower general indices for quality of life in a group of individuals older than 65. Nevertheless, they found that more advanced age was associated with better indices of mental health. The present study did not indicate any association between age and quality of life scores, except for a discrete protective effect in the environmental domain for those older than 60 . This protective effect is difficult to explain because of the sampling selection bias. It may be that the older individuals who voluntarily approached the volunteers are generally more concerned about their health.

Some studies have described the adverse effects of obesity on quality of life. ${ }^{29,30}$ Studies have pointed to reduced physical functionality, health problems, body aches, and poor psychosocial parameters. ${ }^{31-36}$ In our study, a BMI $\geq 25 \mathrm{~kg} / \mathrm{m}^{2}$ was associated with lower scores in the physical domain. We suggest that this relationship exists because a higher risk of comorbidities, including joint pain and functional incapacity, result from excess weight. Nevertheless, the fact that being overweight or obese did not affect scores in other domains was surprising. Nevertheless, this finding is consistent with a study showing that obesity by itself does not alter quality of life in the emotional field, but it does affect the comorbidities associated with obesity. ${ }^{29}$ Thus, when other factors are controlled, obesity may not alter some quality of life scores. 
Jiang and $\mathrm{Hesser}^{20}$ found that persons presented lower life quality indices in all domains after being dianosed DM. Other studies have similarly revealed the impact of disease on quality of life. ${ }^{37}$ In the present study, we found that DM and dyslipidemia increased the likelihood of lower scores in the physical domain. These diseases require continued treatment and lifestyle changes in order to avoid more advanced stages of DM, which can impede daily activities. However, the presence of DM did not affect scores in the other domains, in contrast to results from the literature..$^{20}$

The role of regular physical activity in disease prevention and health promotion is well known. Regular physical activity has been linked to reduction of coronary artery disease and other chronic diseases, such as DM, osteoporosis, obesity, depression, and cancer of the breast and colon. ${ }^{38}$ In accordance with these data, our results indicate that regular physical exercise was associated with higher scores in the psychological and environmental domains of quality of life. Individuals who exercise show greater concern for health and frequently develop this activity into a form of leisure, which positively influences the emotional state. Nevertheless, it is worth noting the lack of significant association between regular physical activity and scores in the physical domain. While our data do not allow definitive conclusions, we suspect that individuals in our study sample who practice physical activity do so in a playful manner and not in manner that is directed toward effective physical conditioning.

Interestingly, only one-third of the participants reported having access to information on cardiovascular risk factors. This result may suggest that the population is not adequately informed during regular medical consultations or that campaigns on health-related education and disease prevention have not been sufficiently effective. This finding underscores the need for health professionals and public institutions to promote health education of the community in a manner that is extensive, continuous, and effective.

Limitations of the study: The individuals included in the present study were not selected to represent the regional population. The fact that participants actively sought the healthcare services offered at the community event likely introduced biases. For example, it is possible that the participants were more aware of cardiovascular risk because they had already presented with a related disease, such as $\mathrm{DM}$ or $\mathrm{AH}$. In addition, they may be more informed about cardiovascular risk factors than the general population. If this bias actually exists, the results concerning the frequency of the investigated diseases have been overestimated. Nevertheless, the high frequencies of these diseases in our study sample allowed us to detect an association between cardiovascular risk factors and quality of life.

Isolated measures of arterial pressure and glycemia are insufficient for concluding a diagnosis of AH or DM. Nevertheless, the majority of individuals classified as carriers of these diseases self-reported them or confirmed the use of medications for their treatment.

\section{CONCLUSION}

The presence of cardiovascular risk factors is related to lower quality of life. Conversely, male gender and regular physical activity have protective effects on quality of life. These findings suggest that exercise should be further promoted by health-related public programs, with a special focus on women.

\section{ACKNOWLEDGEMENTS}

We are grateful to members of the Heart League of Cardiology-2006/2007 for help with administering the questionnaires, to members of the Academic Center of the Nursing School (CAENF) of the Botucatu Medical School for assistance with the glycemia evaluations, and to the statistician Hélio Rubens de Carvalho Nunes for help with data analysis.

We also thank the Botucatu regional chapter of São Paulo State Society of Cardiology (SOCESP) for support in developing the forms to be filled out by the study participants and for guidance on various aspects of healthcare advice.

\section{REFERENCES}

1. Ministério da Saúde [Internet homepage]. Secretaria Executiva. Informações de Saúde. Morbidade e informações epidemiológicas. Accessed at: http://www.datasus.gov.br/

2. Buss PM. Assistência hospitalar no Brasil (1984-1991): uma análise preliminar baseada no Sistema de Informação Hospitalar do SUS. Inf Epidemiol SUS. 1993;2: 5-44.

3. Bonow RO, Smaha LA, Smith Jr SC, Mensah GA, Lenfant C. The international burden of cardiovascular disease: responding to the emerging global epidemic. [Special Report, World Heart Day 2002]. Circulation. 2002;106:1602-06.
4. National Institute of Health. Morbity and Mortality Chartbook on Cardiovascular, Lung and Blood Service. 1990.

5. Santos Filho RD, Martinez TLR. Fatores de Risco para Doença Cardiovascular: Velhos e Novos Fatores de Risco, Velhos Problemas! Arq Bras Endocrinol Metab. 2002;46:212-14.

6. Nobre RCN, Domingues RZL, Silva AR, Colugnati FAB, Tadde JAAC Prevalências de sobrepeso, obesidade e hábitos de vida associados ao risco cardiovascular em alunos do ensino fundamental. Rev Assoc Med Bras. 2006;52:118-24. 
7. Grundy SM, Pasternak R, Greenland P, Smith Jr S, Fuster V. Assessment of cardiovascular risk by use of multiplerisk- factor assessment equations: A statement for healthcare professionals from the American Heart Association and the American College of Cardiology. Circulation. 1999;100:1481-92.

8. Collins R, Peto R, MacMahon S, Hebert P, Fiebach NH, Eberlein KA et al. Blood pressure, stroke, and coronary heart disease. Part 2, Shortterm reductions in blood pressure: overview of randomised drug trials in their epidemiological context. Lancet 1990;335:827-38.

9. Piegas LS, Avezum A, Pereira JCR, Rossi Neto JM, Hoepfner C, Farran JA. Risk factors for myocardial infarction in Brazil. Am Heart J. 2003;146:331-38.

10. Dias da Silva MA, Souza AGMF, Schargodsky H. Fatores de risco para infarto do miocárdio no Brasil. Estudo FRICAS - Arq Bras Cardiol. 1998;71:667-75.

11. Lessa I, Araújo MJ, Magalhães L, Almeida Filho N de, Aquino E, Costa MCR. Simultaneidade de fatores de risco cardiovascular modificáveis na população adulta de Salvador (BA), Brasil. Rev Panam Salud Publica. 2004;16:131-37.

12. Mena-Martin FJ, Martin-Escudero JC, Simal-Blanco F, Carretero-Ares JL, Arzua-Mouronte D, Herreros-Fernandez V. Health-related quality of life of subjects with known and known hypertension: results from the population-based Hortega study. J Hypertension 2003;21:1283-89.

13. Seidl EMF; Zannon CMLC. Qualidade de vida e saúde: aspectos conceituais e metodológicos. Cad. Saúde Pública. 2004;20:580-88.

14. The WHOQOL Group. The World Health Organization quality of life assessment (WHOQOL): position paper from the World Health Organization. Soc Sci Med. 1995;41:1403-10.

15. Nobre MRC. Qualidade de Vida [Editorial]. Arq Bras Cardiol. 1995;64:229-300.

16. The WHOQOL Group. The World Health Organization quality of life assessment (WHOQOL): development and general psychometric properties. Soc Sci Med. 1998;46:1569-85.

17. Fleck MPA, Louzada S, Xavier M, Chachamovich E, Vieira G, Santos $\mathrm{L}$ et al. Aplicação da versão em português do instrumento abreviado de avaliação da qualidade de vida "WHOQOL-bref" Rev. Saúde Pública. 2000;342:178-83

18. Saupe R, Nietche EA, Cestari ME, Giorgi MDM, Krahl M. Qualidade de vida dos acadêmicos de enfermagem. Rev Latino-am Enfermagem 2004 julho-agosto; 12:636-42.

19. Mion jr, D, Machado CA, Gomes MAM, Nobre F, Kohlmann jr O, Amodeo C etal. IV Diretrizes Brasileiras de Hipertensão Arterial. Arq Bras Cardiol. 2004;82(suppl IV):7-22.

20. Gus I, Harzheim E, Zaslavsky C, Medina C, Gus M. Prevalence, Awareness, and Control of Systemic Arterial Hypertension in the State of Rio Grande do Sul. Arq Bras Cardiol. 2004;83:429-33.

21. Matos AC, Ladeia AM. Assessment of Cardiovascular Risk Factors in a Rural Community in the Brazilian State of Bahia. Arq Bras Cardiol. 2003;81:297-302.

22. Nunes Filho JR, DebastianiD, Nunes AD, Peres KG. Prevalência de Fatores de risco Cardiovascular em Adultos de Luzerna, Santa Catarina, 2006. Arq Bras Cardiol. 2007;89:319-24
23. Cavalcante MA, Bombig MTN, Luna Filho B, Carvalho ACC, Paola AAV, Povoa R. Qualidade de Vida de Pacientes Hipertensos em Tratamento Ambulatorial. Arq Bras Cardiol. 2007;89:245-50.

24. Rozanski A, Blumenthal JA, Davidson KW, Saab PG, Kubzansky L.The epidemiology, pathophysiology, and management of psychosocial risk factors in cardiac practice: The emerging field of behavioral cardiology. J Am Coll Cardiol. 2005;45:637-51.

25. Jiang Y, Hesser JE. Associations between health-related quality of life and demographics and health risks. Results from Rhode Island's 2002 behavioral risk factor survey. Health and Quality of Life Outcomes. 2006; 4:1-10.

26. Pereira RJ, Cotta RMM, Franceschini SCC, Ribeiro RCL, Sampaio RF, Priore, SE et al. Contribuição dos domínios físico, social, psicológico e ambiental para a qualidade de vida global de idosos. Rev Psiquiatr RS. 2006;28:27-8.

27. Galvão LLLF, Farias MCF, Azevedo PRM, Vilar MJP, Azevedo GD. Prevalência de transtornos mentais comuns e avaliação da qualidade de vida no climatério. Rev Assoc Med Bras. 2007;53:414-20.

28. Alvarez SE, Friedman EJ, Beckman E, Blackwell M, Chinchila NS, Lebon $\mathrm{N}$ et. al. Encontrando os feminismos latino-americanos e caribenhos. Rev Estud Fem. 2003;11:541-75.

29. Kolotkin RL, Meter K, Williams GR. Quality of life and obesity. Obes Rev. 2001;2:219-29.

30. Kushner RF, Foster GD. Obesity and quality of life. Nutrition. 2000;16:947-952.

31. Mathias SD, Williamson CL, Colwell HH, Cisternas MG, Pasta DJ, Stolshek BS et al. Assessing health-related quality-of-life and health state preference in persons with obesity. Qual Life Res. 1997;6:311-22.

32. Le Pen C, Levy E, Loos F, Banzet MN, Basdevant A. "Specific" scale compared with "generic" scale: a double measurement of the quality of life in a French community sample of obese subjects. J Epidemiol Community Health. 1998;52:445-50.

33. Kolotkin RL, Head S, Hamilton M, Tse CJ. Assessing the impact of weight on quality of life. Obes Res. 1995;3:49-56.

34. Butler GS, Vallis TM, Perey B. The Obesity Adjustment Survey: development of a scale to assess psychological adjustment to morbid obesity. Int J Obes Relat Metab Disord. 1999;23:505-11.

35. Barofsky I, Fontaine KR, Cheskin LJ. Pain in the obese: impact on health-related quality of life. Ann Behav Med. 1998;19:408-10.

36. Larsson U, Karlsson J, Sullivan M. Impact of overweight and obesity on health-related quality of life - a Swedish population study. Int J Obes Relat Metab Disord. 2002;26:417-24.

37. McHorney CA, Ware JE, Raczek A. The MOS 36-item short-form health survey (SF-36) II: psychometric and clinical tests of validity in measuring physical and mental health constructs. Med Care. 1993;31:247-63.

38. Thompson PD, Buchner D, Pina IL, Balady GJ, Williams MA, Marcus $\mathrm{BH}$ et al. Exercise and physical activity in the prevention and treatment of atherosclerotic cardiovascular disease: a statement from the Council on Clinical Cardiology (Subcommittee on Exercise, Rehabilitation, and Prevention) and the Council on Nutrition, Physical Activity, and Metabolism (Subcommittee on Physical Activity). Circulation. 2003;107:3109-116. 